EVS28

KINTEX, Korea, May 3-6, 2015

\title{
Experimental behaviour of Li-ion and supercapacitors cells for HEVs under standardized and tailored-life cycle testing
}

\author{
Mario Conte, Fabrizio Alessandrini, Manlio Pasquali, Ennio Rossi, Vincenzo Sglavo, \\ Francesco Vellucci \\ Italian National Agency for New Technologies, Energy and the Sustainable Economic Development (ENEA), C.R. \\ Casaccia, Via Anguillarese301,00123 Roma, Italy, mario.conte@enea.it
}

\begin{abstract}
A large European Project, named HCV (Hybrid Commercial Vehicles) started in January 2010 with the participation of 18 European organizations (vehicle manufacturers, components integrators and suppliers, and research organizations) and with the scope to develop and demonstrate the next generation of hybrid heavy duty (HD) commercial vehicles by using various types of storage systems. In this project, seven research (AIT, ENEA, University of Pisa) and industrial organizations (IVECO, Volvo, Magna, DimacRed) from various European countries have been working together to experimentally analyse, with electrical and safety tests, the behaviour of Li-ion and supercapacitor cells and modules to support the design and the optimization of the final storage systems to be installed on different HEV (Hybrid Electric Vehicles): urban buses and commercial vans.

This paper summarizes the experimental work carried out at ENEA and is focussed on electrical and safety tests, which fully characterized the selected storage samples according to conventional and testing procedures, tailored on the technical specifications of the HEV under development. Initially, basic characterization testing, together with safety tests, confirmed the technical performances of the two storage technologies, and, subsequently, project-specific testing, including cycle life and accelerating procedures, verified the behaviour in operating conditions, adapted to the selected HEV. The final results substantiated the suitability of the storage systems in powering the commercial hybrid vehicles under development in $\mathrm{HCV}$ project, and gave innovative inputs to the definition and validation of mathematical models and control algorithms, not analysed in this paper, to be used in the BMS (battery management systems) for both storage technologies, suitable for thermal management and overall storage control.
\end{abstract}

Keywords: HEV, energy storage, lithium-ion, super capacitor, testing 


\section{Introduction}

The hybrid electric vehicles (HEV) can significantly contribute in containing exhaust emissions in urban areas, with improved energy efficiency. In particular, the use of urban buses and commercial vans in hybrid configurations is highly promising in passengers and goods transport in urban areas, because the typical travel missions stabilize the operating conditions of these types of drivetrains around wellcontrolled optimal working points. The current research and development activities on advanced heavy duty (HD) hybrid vehicles (buses, trucks and commercial vans) are aimed in most cases at extremely challenging requirements, with technological and economical breakthroughs and subsequent industrialization concentrated on the drivetrain technologies with the possibilities to use alternative or complementary storage systems to perform key functions (traction assistance to conventional internal combustion engine, regenerative braking and, eventually, pure electric traction mode for a limited range). A large European Project, named HCV (Hybrid Commercial Vehicles) and partially funded by the European Commission (EC), was started in January 2010 and was completed in 2014, with the participation of 18 European organizations (vehicle manufacturers, components integrators and suppliers, research organizations). The HCV project had the scope to demonstrate the status of current HD HEVs in real applications and develop the next generation of cost-effective and more efficient hybrid commercial vehicles by using various types of storage systems, with the final practical objectives to reduce powertrain cost of about $40 \%$ and fuel consumption of $30 \%$ in a city bus cycle, compared with present hybrid bus technologies. To better assist storage systems suppliers and assemblers and vehicles manufacturers in optimizing components, subsystems and, eventually, complete drivetrains, a dedicated "Energy Storage Systems" SubProject was carried out for the experimental evaluation and in-depth characterization of the technical performances and reliability in normal and extreme conditions of the storage systems in relation to the specific HEV architectures, with focus on two energy storage technologies: lithium-ion batteries and electrochemical supercapacitors (SC) [1, 2]. Seven research (AIT - Austrian Institute of Technology, ENEA, University of Pisa) and industrial organizations (IVECO, Volvo, Magna, DimacRed) from three
European countries have been working together to experimentally analyse, with electrical and safety tests, the behaviour of Li-ion and supercapacitor cells and modules to support the design and the optimization of the final storage systems to be installed on different HEV (Hybrid Electric Vehicles): urban buses and commercial vans. One of the main objectives of these activities on energy storage has been to verify the basic performances of the samples with electrical, thermal and safety/abuse testing and compare life behaviour in standardized or accelerated duty cycles with respect to the use in driving profiles tailored on the HCV vehicles. ENEA (Italian National Agency for New technologies, Energy and Economic Sustainable Development) has been involved in various phases of the activities by contributing to identifying and defining technical specifications and adapting testing procedures to the specific need of the project and, finally, executing electrical tests on the cells and assembled modules, on which ENEA also executed mechanical tests (vibrations).

This paper reports about the main final results achieved by ENEA during basic characterization, life and vibration testing on both storage technologies, based on the testing procedures, tailored on the specific HEV configurations and targeted performances. Initially, the samples under tests and the summary of the testing procedures, reported in details in $[3,4,5]$, are described. Subsequently, the main results for each test type are shortly reported and analysed with main conclusions also related to the definition and validation of mathematical models and algorithms for management and control of both storage technologies, not analysed in this paper, but more described in $[6,7,8]$.

\section{The reference HEV and the samples under tests}

There were two $2^{\text {nd }}$ generation HEVs under development in the HCV project that have been used as reference HEVs (both parallel hybrid vehicles) with well-defined basic technical specifications applied in the design and test of the ESS (Energy Storage System). Altra-IVECO has improved a Daily 5-ton delivery van, equipped with an ESS able to supply a maximum power (in charge and discharge) of $45 \mathrm{~kW}$, a maximum voltage and current of about $300 \mathrm{~V}$ and $200 \mathrm{~A}$ and a delivered energy up to the end-of-life (EOL) of $800 \mathrm{Wh}$. These technical specifications apply to the two alternative ESS, one based on Li-ion 
technology and the other one on SC. Volvo has built up a 12-m city bus (a second generation parallel hybrid) only using an Li-ion ESS with the following specifications: a peak power of 90 $\mathrm{kW}$ over the life $(120 \mathrm{~kW}$ at Beginning-Of-Life, $\mathrm{BOL}$ ), a rated voltage of $633 \mathrm{~V}$, a peak current of $150 \mathrm{~A}$, and an available energy (for a complete discharge) also at end-of-life (EOL) of $1200 \mathrm{Wh}$. Samples of commercial cells of both technologies (Li-ion and SC) were made available for safety and electrical testing. The lithium-ion cell technology used in the project is based on lithium iron phosphate (LFP) cathode, while the SC cells were based on a more conventional commercial EDLC (Electric Double Layer Capacitor) carbon/carbon technology. A set of $200 \mathrm{Li}$ cells (an advanced generation with a nominal capacity of $4.4 \mathrm{Ah}$ ) have been made available together with about $100 \mathrm{SC}$ cells (with a nominal capacitance of $3000 \mathrm{~F}$ ). Table 1 shows basic characteristics of $\mathrm{Li}$ and $\mathrm{SC}$ cells.

Table 1: Technical properties of HCV Li-ion and SC cells

\begin{tabular}{|l|c|c|}
\hline \multicolumn{1}{|c|}{ Properties } & Li Cell & SC cell \\
\hline Capacity/Capacitance & $4.4 \mathrm{Ah}$ & $3000 \mathrm{~F}$ \\
\hline Nominal Voltage & $3.3 \mathrm{~V}$ & $2.7 \mathrm{~V}$ \\
\hline Mass (average) & $205 \mathrm{~g}$ & $510 \mathrm{~g}$ \\
\hline Diameter & $32 \mathrm{~mm}$ & $60.7 \mathrm{~mm}$ \\
\hline Length & $113 \mathrm{~mm}$ & $138 \mathrm{~mm}$ \\
\hline Energy & $14.5 \mathrm{Wh}$ & $3.04 \mathrm{Wh}$ \\
\hline $\begin{array}{l}\text { Specific } \\
\text { Energy/Energy } \\
\text { content }\end{array}$ & $75 \mathrm{Wh} / \mathrm{kg}$ & $5.96 \mathrm{Wh} / \mathrm{kg}$ \\
\hline $\begin{array}{l}\text { Power (25C, } \\
50 \% \text { SOC, } 10 \mathrm{sec})\end{array}$ & $578 \mathrm{~W}$ & $3020 \mathrm{~W}$ \\
\hline $\begin{array}{l}\text { Specific Power }(25 \mathrm{C}, \\
50 \% \text { SOC, } 10 \mathrm{sec})\end{array}$ & $2979 \mathrm{~W} / \mathrm{kg}$ & $12300 \mathrm{~W} / \mathrm{kg}$ \\
\hline $\begin{array}{l}\text { DC Resistance }(25 \mathrm{C}, \\
50 \% S O C, 10 \mathrm{sec})\end{array}$ & $4.5 \mathrm{~m} \Omega$ & $0.29 \mathrm{~m} \Omega$ \\
\hline
\end{tabular}

During the progress of the project, an industrial assembling process (not part of the project, but as internal industrial innovation in Magna) was developed and applied for assembling Li-ion modules, while for the SC modules an initial generation was improved and a $2^{\text {nd }}$ and a $3^{\text {rd }}$ generation were assembled in 2013. A set of 14 Li-ion modules were prepared in the same design chosen for the final system to be installed on the HEV with these final characteristics: 18 cells in series, capacity of $8.5 \mathrm{Ah}$, voltage of $59.4 \mathrm{~V}$, energy of $505 \mathrm{Wh}$, peak power of $11.25 \mathrm{~kW}$, and an overall weight with some sensors and connectors of about $10 \mathrm{~kg}$.

Similarly, ten SC modules of two different generations were also assembled and made available for testing: one without case and the second one with the case (a third one was also prepared for comparison using a different case material) with the same specifications of the ones used in the final system. The SC modules have these technical specifications: six cells in series, capacitance of $500 \mathrm{~F}$, voltage of $16.2 \mathrm{~V}$, specific energy of $5.96 \mathrm{Wh} / \mathrm{kg}$, specific power of 5.9 $\mathrm{kW} / \mathrm{kg}$, and an overall weight with some sensors and connectors of about $4.4 \mathrm{~kg}$.

\section{Electrical testing}

The electrical test procedures of Li-ion and SC cells and modules have been organized, after a survey of existing standard and procedures in five different test sequences aimed at different testing scopes $[4,5]$ :

- General preparation tests.

- Basic characterizations for the designed operating conditions of the HCV demonstrators.

- Ageing - accelerated life testing to estimate cell life under with degradation accelerating factors to give quick feedback to system design and road demonstrations phases.

- Management-oriented tests on a small set of series-connected cells (or module with balancing electronic board) to study management needs.

- Input measurements for modelling to collect operating data for the definition and validation of mathematical models.

To achieve a proper adaptation of testing procedures to the samples' characteristics, the technical specifications of the complete $\mathrm{HEV}$ storage systems have been scaled down and adapted to the sample sizes (cells and modules) by using a Battery Size Factor (BSF), intended as an integer number, which is the minimum number of cells expected to be required to meet all the performance and life targets. For example, in the case of the Altra HEV Li-ion ESS (a storage system of $45 \mathrm{~kW}$ ), the BSF has been roughly rounded to 192, while if the ESS is based on SC the BSF is 144 . These BSF are constant for all the tests.

\subsection{Electrical testing on Li-ion cells}

ENEA work has been concentrated on the preparation and execution of the electrical testing on cells with the set-up of a new testing equipment, integrated with a climatic chamber used for controlling the working temperature of the sample. More than $100 \mathrm{Li}$-ion cells has been characterized and continuously monitored, according to the basic characterization tests to 
verify technical specifications. Due to the very repeatable technical characteristics of the $\mathrm{Li}$ cells, it was not necessary to establish any specific criterion for cell selection from the available set to be used for electrical testing. The Li-ion cells have undergone the following tests:

1. Basic characterization (physical characteristics, capacity determination, fast charge, self-discharge, initial parameter check-up)

2. Life testing of different types:

a. Life testing at various temperatures with high power profiles

b. Accelerated

c. Calendar life

d. Life testing at various temperatures with ALTRA-

IVECO driving cycle

3. Periodic parameter check-ups

\subsubsection{Basic characterization of Li-ion cells}

Some examples of the measurements of the main basic characteristics are described hereafter. The capacity determination, after electric formation, was carried out for seven different discharge current rates (from $\mathrm{C} / 2$ to $20 \mathrm{C}$, where $\mathrm{C}$ is the nominal capacity of the cell). The capacity and the specific energy of each cell at various discharge rates were in line with the manufacturer data, as shown in Table 2 and in Table 3.

Table 2: Capacity of various $\mathrm{Li}$-ion cells at different discharge rates

\begin{tabular}{|c|c|c|c|c|c|c|c|}
\hline ID \# & $\begin{array}{c}\mathrm{C} / 2 \\
{[\mathrm{Ah}]}\end{array}$ & $\begin{array}{c}1 \mathrm{C} \\
{[\mathrm{Ah}]}\end{array}$ & $\begin{array}{c}2 \mathrm{C} \\
{[\mathrm{Ah}]}\end{array}$ & $\begin{array}{c}5 \mathrm{C} \\
{[\mathrm{Ah}]}\end{array}$ & $\begin{array}{c}10 \mathrm{C} \\
{[\mathrm{Ah}]}\end{array}$ & $\begin{array}{c}15 \mathrm{C} \\
{[\mathrm{Ah}]}\end{array}$ & $\begin{array}{c}20 \mathrm{C} \\
{[\mathrm{Ah}]}\end{array}$ \\
\hline HCV-102 & 4.34 & 4.31 & 4.27 & 4.20 & 4.14 & 4.10 & 4.06 \\
\hline HCV-104 & 4.28 & 4.25 & 4.22 & 4.15 & 4.09 & 4.05 & 4.02 \\
\hline HCV-105 & 4.34 & 4.33 & 4.30 & 4.23 & 4.18 & 4.14 & 4.11 \\
\hline HCV-106 & 4.34 & 4.33 & 4.30 & 4.23 & 4.18 & 4.14 & 4.11 \\
\hline
\end{tabular}

Table 3: Initial specific energy of Li-ion cells at various discharge rates

\begin{tabular}{|c|c|c|c|c|c|c|c|}
\hline ID \# & $\begin{array}{c}\mathrm{C} / 2 \\
\mathrm{SE}^{*}\end{array}$ & $\begin{array}{c}1 \mathrm{C} \\
\mathrm{SE}^{*}\end{array}$ & $\begin{array}{c}2 \mathrm{C} \\
\mathrm{SE}^{*}\end{array}$ & $\begin{array}{c}5 \mathrm{C} \\
\mathrm{SE}^{*}\end{array}$ & $\begin{array}{c}10 \mathrm{C} \\
\mathrm{SE}^{*}\end{array}$ & $\begin{array}{c}15 \mathrm{C} \\
\mathrm{SE}^{*}\end{array}$ & $\begin{array}{c}20 \mathrm{C} \\
\mathrm{SE}\end{array}$ \\
\hline $\begin{array}{c}\mathrm{HCV}- \\
102\end{array}$ & 57.08 & 56.15 & 55.13 & 52.95 & 50.44 & 48.55 & 46.93 \\
\hline $\begin{array}{c}\mathrm{HCV}- \\
104\end{array}$ & 56.43 & 55.66 & 54.69 & 52.57 & 50.15 & 48.23 & 46.66 \\
\hline $\begin{array}{c}\mathrm{HCV}- \\
105\end{array}$ & 57.70 & 57.36 & 56.38 & 54.20 & 51.95 & 50.23 & 48.61 \\
\hline $\begin{array}{c}\mathrm{HCV}- \\
106\end{array}$ & 57.26 & 56.83 & 55.88 & 53.72 & 51.50 & 49.81 & 48.24 \\
\hline
\end{tabular}

$S E^{*}=$ Specific energy $=W h / k g$

The self-discharge test was carried out for two different rest periods (48h and 120h) and two different temperatures. Table 4 summarizes the results of self-discharge tests on some cells by reporting the capacity, measured at the end of the test at RT.

Table 4: Self-discharge test results

\begin{tabular}{|l|c|c|c|}
\hline \multicolumn{1}{|c|}{ Cell Code } & \multicolumn{2}{|c|}{ Capacity $(\mathrm{Ah})$} & Temp \\
\hline After a rest of & $48 \mathrm{~h}$ & $120 \mathrm{~h}$ & $\left({ }^{\circ} \mathrm{C}\right)$ \\
\hline HCV102 & 4.34 & 4.31 & 23 \\
\hline HCV104 & 4.28 & 4.25 & 23 \\
\hline HCV105 & 4.29 & 4.28 & 23 \\
\hline HCV106 & 4.31 & 4.29 & 23 \\
\hline
\end{tabular}

Table 4 confirms a limited self-discharge in all the testing conditions.

\subsubsection{Life testing of Li-ion cells}

Life testing of Li-ion cells was the core activity of the electrical testing with the scope to verify the behaviour in standard and $\mathrm{HCV}$-specific operating conditions and to estimate degradation of the cell performances (for modelling purposes) and data useful for the energy storage modules/systems integrator and the end users. Life tests were carried out according to the conventional and HCVspecific test sequences: Life cycle test based on $\mathrm{HCV}$ profiles, Calendar life in off-load conditions and Accelerated High power battery cycling, with selected parameters (temperature and power profiles) for fast degradation of cell performances. All these tests were periodically interrupted to perform control checks of the basic characteristics of the cells.

The HCV-specific Life Cycle Testing was carried out mostly using the proposed HCV commercial van profile (a micro-cycle of $167 \mathrm{~s}$, to be repeated 18 times for one hour work and 180 times for one day work). The power profile of the entire ESS was adequately reduced at cell level using a scale down factor (BSF = Battery Size Factor), based on the number of cells in the fully system, as shown in Figure 1.

The sample under test has been cycled in sequence at three different temperatures $\left(23^{\circ} \mathrm{C}, 30^{\circ} \mathrm{C}\right.$ and $40{ }^{\circ} \mathrm{C}$ and at a State-of-Charge - SOC of $75 \%$ ) with an initial and a final parameter check-up. At the end of the life testing 17,690 Altra microcycles (corresponding to about 100 working days in three different seasons of the year: one cold, one 
warm and one intermediate) were completed.

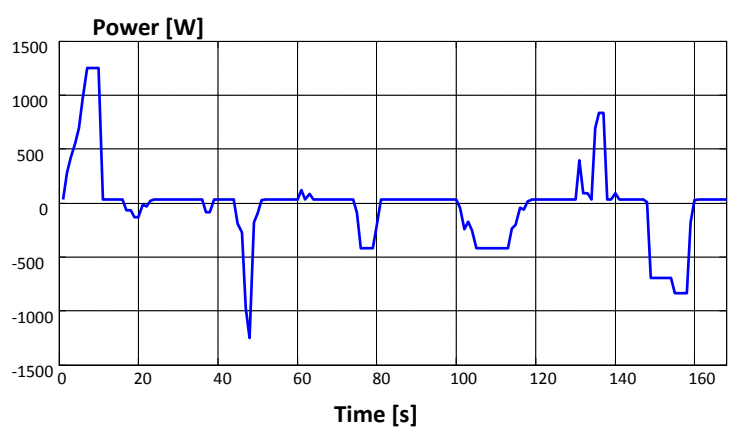

Figure 1: Altra power micro-cycle scaled down at cell level

In details, the cell was cycled for 7,150 microcycles at $23{ }^{\circ} \mathrm{C}, 6,590$ micro-cycles at $30{ }^{\circ} \mathrm{C}$ and 3,950 micro-cycles at $40{ }^{\circ} \mathrm{C}$. The equivalent travelled distance for the complete testing period is $17,690 \mathrm{~km}$ in three different operating temperatures.

The cell was instrumented with a temperature sensor glued at the centre of the sample under test. The maximum temperature reached at the end of the test at $23{ }^{\circ} \mathrm{C}$ was $28.5^{\circ} \mathrm{C}$, and also for the other testing temperatures, the variations never reached values considered unsafe or outside the limits recommended by the manufacturer. At parameter check-ups and at the end of the complete ALTRA test sequence, the loss of capacity has been very small with a variation of $1.25 \%$ (from 4.22 Ah down to 4.17 $\mathrm{Ah})$.

The analysis of results at periodic parameter check-ups confirms the limited impact of the ALTRA test profile on the basic performances of the Li-ion cells and their negligible degradation.

The Calendar Life Cycle Testing has been carried out on four different $\mathrm{Li}$-ion cells at two temperatures $\left(45^{\circ} \mathrm{C}\right.$ and $\left.60{ }^{\circ} \mathrm{C}\right)$. The cells were put in oven in OCV (open circuit voltage) during the storage time, each lasting about 6 weeks. In total each cell has undergone a calendar life lasting 24 weeks (four periods of 6-week each). Initially and after each storage period, a parameter check-up was carried out on each cell. During the calendar life at various temperatures and SOC, the key technical performances of the cells have changed even significantly, particularly at the highest temperatures. The OCV (Open Circuit Voltage), the internal resistance (in charge and discharge) as well as the capacity have largely degraded.

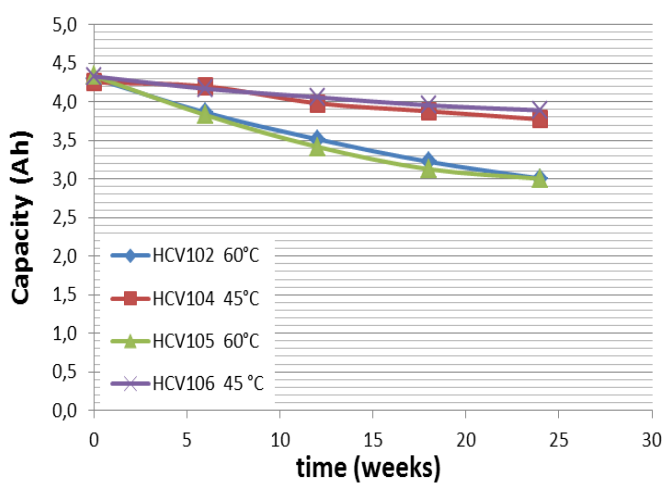

Figure 2: Capacity decline after storage at high temperature $\left(45^{\circ} \mathrm{C}\right.$ and $\left.60^{\circ} \mathrm{C}\right)$

Figure 2 shows the capacity degradation at high temperature, measured during parameter checkups, at beginning and at intermediate stops of storage of 6-week periods.

The negative effects of storage at higher temperature $\left(60{ }^{\circ} \mathrm{C}\right)$ and low SOC are confirmed by comparing test results.

Similar analysis has been carried out also for other key parameters. In the case of the theoretical discharge power in function of SOC, the variation, as shown in Figure 3, increases significantly at low SOC after long storage at higher temperature.

Analogously, the experimental data related to the internal resistance (IR, in charge and discharge) in function of SOC confirm the limited variation occurring at $45{ }^{\circ} \mathrm{C}$ and a larger fluctuation at low SOC after long storage at the temperature of $60^{\circ} \mathrm{C}$.

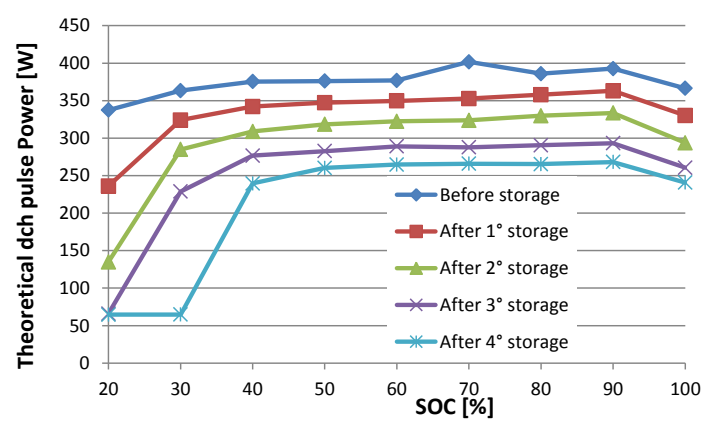

Figure 3: Theoretical discharge power vs SOC during calendar life tests of Cell HCV102 $\left(24\right.$ weeks at $\left.60^{\circ} \mathrm{C}\right)$

The Accelerated High power battery cycling was performed on two cells by applying continuously a high power profile (in Figure 4 current and voltage profiles are represented). Three test sequences were repeated on the cells, each lasting 6-7 weeks and starting from an SOC of 55\%, as planned, with an initial and periodic parameter check-ups (at the end of each test sequence). Each of the three test sequences was carried out at a different 
temperature: $23^{\circ} \mathrm{C}, 30{ }^{\circ} \mathrm{C}$ and $40{ }^{\circ} \mathrm{C}$. Table 5 summarizes the entire test sequence.

At beginning and at the end of each test sequence a parameter check-up has been performed with the acquisition and calculation of the main performance characteristics of each cell under test.

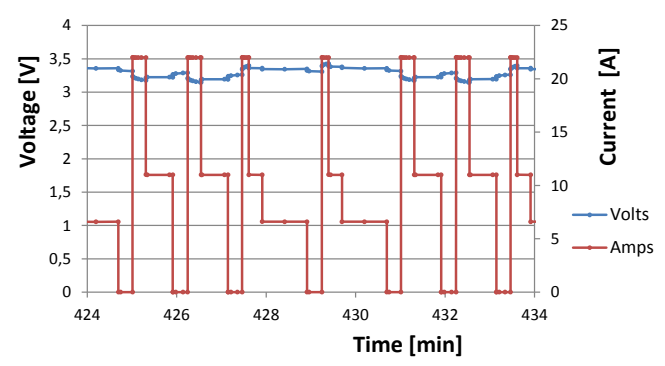

Figure 4: Current and voltage profiles for high power life testing

Table 5: Summary of the High Power life cycle testing for two different Li-ion cells

\begin{tabular}{|c|c|c|c|}
\hline \multicolumn{4}{|c|}{$1^{\text {st }}$ Test sequence } \\
\hline$\#$ & Days & Cycles & $T,{ }^{\circ} \mathrm{C}$ \\
\hline 111 & 48 & 9099 & 23 \\
\hline 112 & 48 & 9090 & 23 \\
\hline \multicolumn{4}{|c|}{$2^{\text {nd }}$ Test sequence } \\
\hline$\#$ & Days & Cycles & $T,{ }^{\circ} \mathrm{C}$ \\
\hline 111 & 40 & 8398 & 30 \\
\hline 112 & 40 & 8398 & 30 \\
\hline \multicolumn{5}{|c|}{$3^{\text {rd }}$ Test sequence } \\
\hline$\#$ & Days & Cycles & $T,{ }^{\circ} \mathrm{C}$ \\
\hline 111 & 42 & 9240 & 40 \\
\hline 112 & 42 & 9240 & 40 \\
\hline
\end{tabular}

The behaviour of the cells does not change significantly during high power cycle testing at any temperature. These results are confirmed also comparing the other technical characteristics measured or calculated during parameter checkups. Only for exemplification of this behaviour, Figure 5 compares the capacity variations of the two cells before and after high power cycling.

Also the attempt to accelerate cell degradation with the temperature has been limitedly effective because the used high temperature of $40{ }^{\circ} \mathrm{C}$ has not been able to accelerate significantly ageing of the cells together with the number of high power cycles.

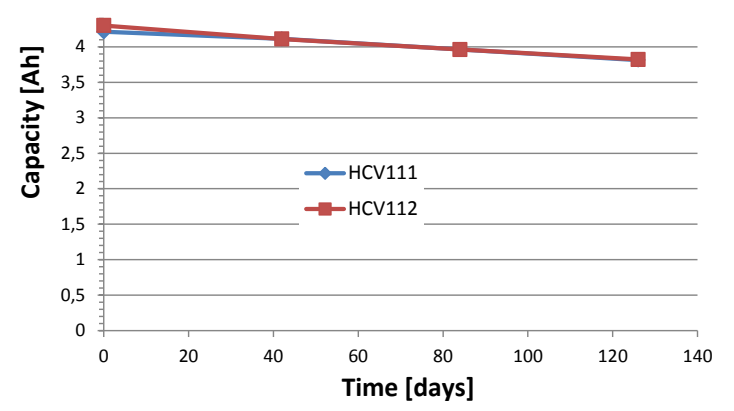

Figure 5: Comparison of capacity during high power test at $23{ }^{\circ} \mathrm{C}$ of two Li-ion cells

To better analyse the degradation of cell performances from an electrochemical point of view, various EIS (Electrochemical Impedance Spectroscopy) have been registered by means of a dedicated FRA (Frequency Response Analyser).

For comparison the EIS spectra have been recorded before and after cycling to verify the variations of the cell impedance. Despite of the number of spectra measured and analysed on different cells, the focus has been put on the test and the cell having the major decline during accelerated calendar testing. With these measurements, there was confirmation of a more significant degradation during calendar life at 60 ${ }^{\circ} \mathrm{C}$.

\subsection{Electrical testing on Li-ion modules}

The focus of ENEA activities has been concentrated on the electrical testing of the Li-ion modules, with and without the balancing circuit, for evaluating the behaviour during cycling and under accelerating conditions for design support and modelling purposes. After arrival, all the modules have been measured and verified in terms of physical size (weight and volume), voltage and visual inspection. Electrical tests have been carried out on the new 8-channel MACCOR 4000 Series, specifically designed and built up (with integrated FRA = Frequency Response Analyzer for EIS = Electrochemical Impedance Spectroscopy) for ENEA, while various climatic chambers were used for all the tests, including accelerated calendar (storage) and cycle life tests at various temperatures.

The Electric Formation and initial characterization have been carried out on all the modules by measuring the capacity at various discharge rates. The maximum current reached during this test has been $33.3^{\circ} \mathrm{C}$. Similarly, the capacity determination was carried out at a lower discharge rate $(2 \mathrm{C}$-rate instead of 5C-rate). 
In total, 194 complete standard life cycles have been performed to optimize the standard cycle for the specific testing needs (continuous testing without interruptions) and, then, verify the cell voltage dispersion and equalization needs. Figure 6 presents the discharge capacity measured during life cycling with a standard cycle. It is evident in Figure 6 that there is a significant fluctuation in the capacity values up to the $90^{\text {th }}$ cycle, due to the continuous corrections on the module voltage to reach a satisfying compromise between the overall capacity delivered by the module with the recommended limit for the voltage of each cell.

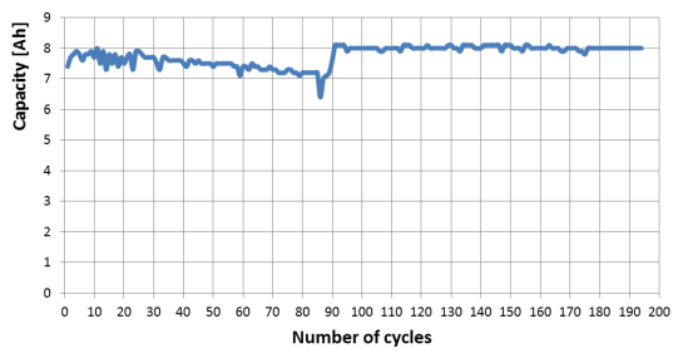

Figure 6: Discharge capacity variation during life testing with a standard cycle

Life cycle testing has been repeated by applying the ALTRA micro-cycle, adequately scaled down to the module size, by using the same procedure used for the cells. The entire life testing lasted 140 equivalent working days (more than $50 \%$ of the targeted 250 working days/year), corresponding to 25,200 micro-cycles and travelled $\mathrm{km}$ (each micro-cycle was equivalent to a travelled distance of $1 \mathrm{~km}$ ).

The parameter check-ups results are summarized in Figure 7 that reports the capacity and energy trends at the verification points, measured with a $1 \mathrm{C}$ discharge rate. No significant decline of performance has been recorded confirming the high maturity of the cells and the industrial level of the assembly process.

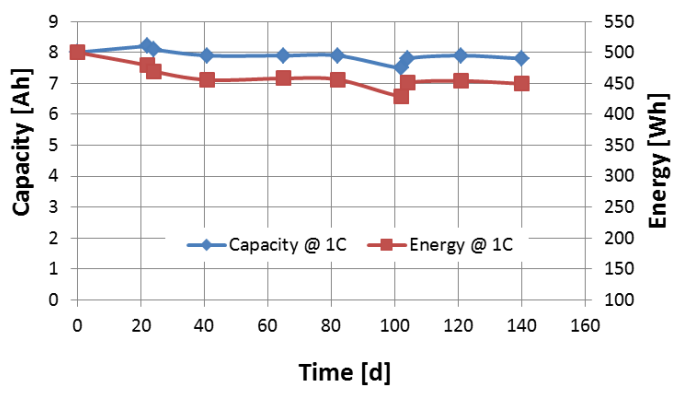

Figure 7: Li module capacity and energy at parameter check-ups with a $1 \mathrm{C}$ discharge rate
The module under test has been also thermally controlled with infrared camera. Figure 8 contains an example of numerous (tens) thermographs taken during life testing.

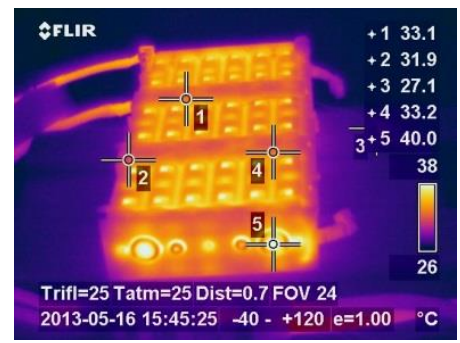

Figure 8: Li module thermographs during life testing

The temperature increase is well below the maximum recommended value of $55{ }^{\circ} \mathrm{C}$, even considering that there is no thermal conditioning system applied to the module.

The overall testing analysis on modules gave indications about the modes of cell equalization by using a passive balancing circuit, with possible feedback to the final battery management (BMS) strategy, including thermal control needs.

\subsection{Electrical testing on SC cells}

The test activities have been carried out in the ENEA SC Test Facility, able to perform electrical and thermal testing on single cells and small modules. During the cell testing, the external temperature of the SC cell is measured with a dedicated sensor.

Figure 9 displays the test control screen with control data and results elaboration with a continuous vision of the sample under test.

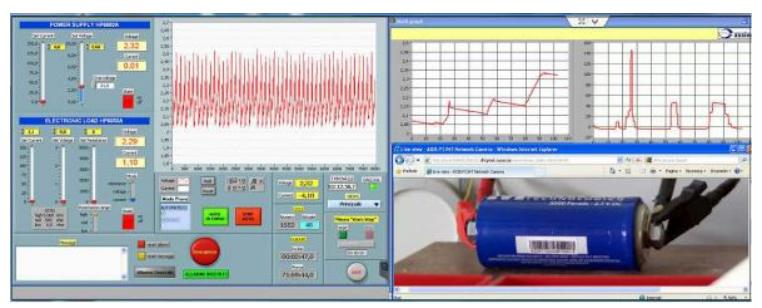

Figure 9: Test control display with data elaboration and sample vision

The SC test plan included the following electrical tests:

1. Basic characterization

a. Capacitance determination

b. Internal resistance $(\mathrm{ESR}=$

Equivalent Series Resistance)

c. Peak power

d. Fast charge and discharge

e. Self-discharge 
2. Accelerated life cycling tests at various temperatures with ALTRA-IVECO driving cycle

3. Intermediate parameter check ups

\subsubsection{Basic characterization of $\mathrm{SC}$ cells}

After initial formation cycles (a few complete standard cycles, charge/discharge, repeated to verify nominal working voltage), the capacitance has been measured at room temperature (RT) and at $40{ }^{\circ} \mathrm{C}$. The calculated value at $\mathrm{RT}$ of $3020 \mathrm{~F}$ confirmed the nominal value of $3000 \mathrm{~F}$. The internal resistance $(\mathrm{ESR}=$ Equivalent Series Resistance) was also calculated with a specific test during charge and discharge, giving the following values at RT: $\operatorname{ESR}(\mathrm{ch})=0.426 \mathrm{~m} \Omega$ with a current step of $80 \mathrm{~A}$; ESR(disch) $=0.416 \mathrm{~m} \Omega$ with a current step of $60 \mathrm{~A}$ (the nominal value, indicated by the manufacturer, of ESR (disch) is $0.29 \mathrm{~m} \Omega$ with a current step of $100 \mathrm{~A}$ ).

The fast charge tests have been performed to define the capability in energy storing of the SC in defined current and time ranges. The nominal measured energy content of the cell has been $3.04 \mathrm{Wh}$. Table 6 summarizes the OCV and energy percentage reached at any step of the profile during fast charge.

Table 6: Key measured parameters during fast charge

\begin{tabular}{|l|c|c|c|c|c|c|}
\hline Parameter & \multicolumn{3}{|c|}{$1^{\text {st }}$ step } & \multicolumn{3}{c|}{$3^{\text {rd }}$ step } \\
\hline OCV, V & 0.96 & 1.04 & 1.12 & 1.22 & 1.44 & 1.62 \\
\hline $\begin{array}{l}\text { Energy } \\
\text { content, \% }\end{array}$ & 12.6 & 14.9 & 17.1 & 20.6 & 28.4 & 35.8 \\
\hline
\end{tabular}

The fast discharge tests have been also performed.

Table 7 summarizes the OCV and energy percentage reached at any step of the test profile during fast discharge.

Table 7: Key measured parameters in fast discharge

\begin{tabular}{|l|c|c|c|c|c|c|}
\hline Parameter & \multicolumn{3}{|c|}{$1^{\text {st }}$ step } & \multicolumn{3}{c|}{$3^{\text {rd }}$ step } \\
\hline OCV, V & 2.57 & 2.50 & 2.44 & 2.34 & 2.15 & 1.97 \\
\hline $\begin{array}{l}\text { Energy } \\
\text { content, \% }\end{array}$ & 9.5 & 14.1 & 18.2 & 24.9 & 36.5 & 46.7 \\
\hline
\end{tabular}

The tests confirmed the excellent behaviour of $\mathrm{SC}$ cells during fast charge and discharge rates.

The peak power test was carried out to verify one of the more important features of SC: the high power density. The current and voltage profiles for peak power tests are shown in Figure 10, while Figure 11 summarized the peak power test results.

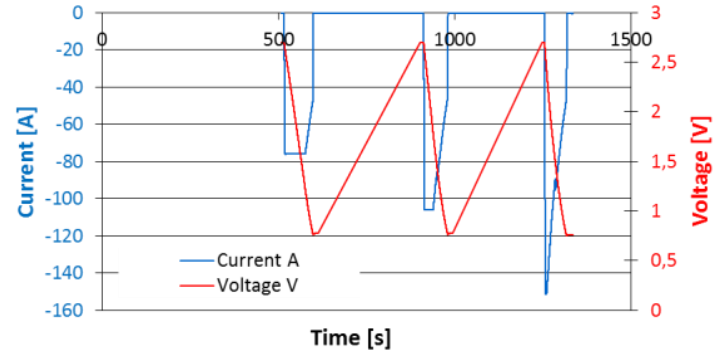

Figure 10: Current and voltage profiles for peak power test

The maximum (specific) peak power reached (for $5 \mathrm{~s}$ ) at a maximum peak current of about $150 \mathrm{~A}$ is about $750 \mathrm{~W} / \mathrm{kg}$ (corresponding to a cell peak power for a continuous period of $5 \mathrm{~s}$ of $370 \mathrm{~W}$ ).

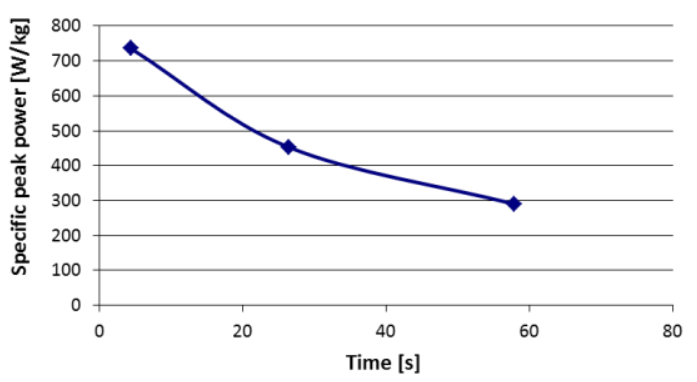

Figure 11: Peak power test results

Finally, the self-discharge behaviour of the SC sample has been analysed, by measuring the voltage for 72 hours at OCV (open circuit voltage), starting from a fully charged cell. The open circuit voltage $(\mathrm{OCV})$ declined as expected without any deviation.

\subsubsection{Life testing of SC cells}

The life cycle tests on the SC cell have been aimed at estimating potential cycle life in HCV application by applying the ALTRA-IVECO driving pattern, referred to the complete vehicle battery power requirement and scaled down from the complete vehicle storage system to the cell level. In addition, in order to accelerate technical performance degradation and better assist modelling definition and validation, the cell has been tested not only at RT but also at the temperature of $40{ }^{\circ} \mathrm{C}$.

In total 21,200 micro-cycles have been performed at RT (and 21,200 km travelled). This number of cycles corresponds to about 118 working days of the Altra HCV commercial vehicle: 18 microcycles amount to 1-h cycle; every working day is composed of $101-\mathrm{h}$ cycles and, in a year, a duty cycle is completed with 250 working days $(45,000$ micro-cycles corresponding to $45,000 \mathrm{~km}$ of 
travelled distance in a year).

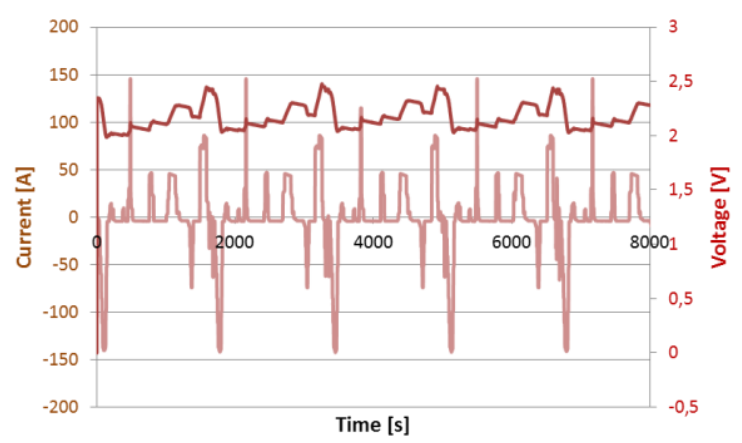

Figure 12: Life cycles after 5,000 micro-cycles at RT on an SC cell

In summary, the cycle life test has simulated about half a year of working time. Figure 12 shows some cycles after the completion of more than 5,000 micro-cycles.

The degradation of basic performances, capacitance and ESR (during charge, $\mathrm{ESR}_{\mathrm{ch}}$, and during discharge, $\mathrm{ESR}_{\mathrm{dch}}$ ), during life cycle testing at RT has been very limited and well below the standard end-of-life criteria (loss of $20 \%$ of nominal capacitance and doubling, or increase of $100 \%$, of ESR). This conclusion is directly derived from the test results summarised in Figure 13, achieved with periodic parameter check-ups.

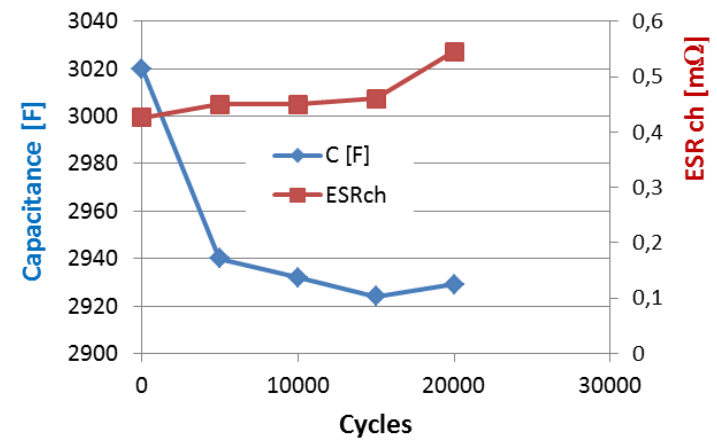

Figure 13: Variations of capacitance and $\mathrm{ESR}_{\mathrm{ch}}$ during cycle life testing

The SC technical performances are limitedly affected by the more severe micro-cycle derived from HCV application in ALTRA hybrid commercial van, demonstrating a high stability that is expected in relation to the declared cycle life of 1,000,000 of complete charge/discharge cycles (based on a standardized profile at constant current in charge and discharge).

The ALTRA cycle life testing has been repeated by increasing the temperature at $40{ }^{\circ} \mathrm{C}$, as possible accelerating factor (as known in literature, together with working voltage close to the maximum allowed). In total, more than 8,000 micro-cycles (equivalent to an additional working period of about 45 days and about $8,045 \mathrm{~km}$ ) have been completed. Combined with the cycle life testing at RT, the SC cell has accumulated a total service life of 163 working days (with respect to a planned year operation of 250 days) with two different temperatures corresponding to the minimum and maximum values required by the Altra-IVECO procedure. Periodically, the capacitance has been measured at RT and also at $40{ }^{\circ} \mathrm{C}$ to verify degradation. For accumulating as many cycles as possible, it was decided to limit the performance control to capacitance measurements, because the other tests during parameter check-ups required longer time. The final results related to the capacitance measurements at periodic parameter check-ups and the comparison with the same results achieved at RT are summarised in Figure 14.

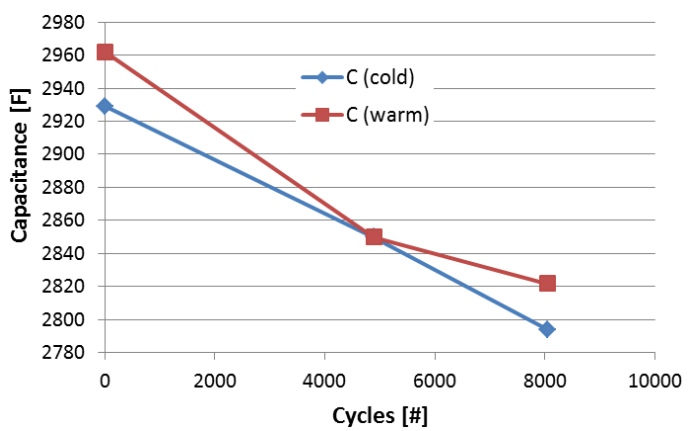

Figure 14: SC capacitance during life cycling at $20^{\circ} \mathrm{C}$ and $40{ }^{\circ} \mathrm{C}$

At the end, the test showed a limited degradation of the capacitance as a combined effect of the life cycling and the higher temperature. After a working period of 164 days at two different temperatures, the SC capacitance was reduced of $4.7 \%$ (the initial value was $3020 \mathrm{~F}$ and the final 2878 F). During all the tests, the SC sample was instrumented with a temperature sensor on the external case to follow all the variations in temperature during any tests: the analysis confirmed, the limited thermal stress (and temperature variation) of the cell case, also due to the not severe working conditions, required by the Altra-IVECO hybrid commercial van application.

\subsection{Electrical testing on SC modules}

ENEA has also carried out basic characterization and life cycle testing on $2^{\text {nd }}$ Generation SC modules. The Electric Formation and initial 
characterization have been carried out on all the modules by measuring the capacity at various discharge rates. The measured capacitance corresponded to the nominal one of $500 \mathrm{~F}$.

The life cycle testing was carried out on the selected SC module by using the ALTRA charge/discharge micro-cycle. This test was originally designed to verify voltage dispersion with a limited number of full charge and discharge cycles, due to the absence of a BMS, able to manage and equalize cell voltage during cycling. However, it was subsequently decided to stress module behaviour by increasing the temperature and continuing life cycling with intermediate quick capacitance controls to try to accelerate degradation and assist the estimation of SOC. In total the life testing lasted 2145 micro-cycles, corresponding to $2,145 \mathrm{~km}(120$ working hours). The tests were limited by the increase of the temperature, which required special attention to avoid exceeding the maximum recommended value. Every three hours of testing there was an interruption for limiting the temperature increase. Figure 15 shows the variation of the temperature during normal life testing.

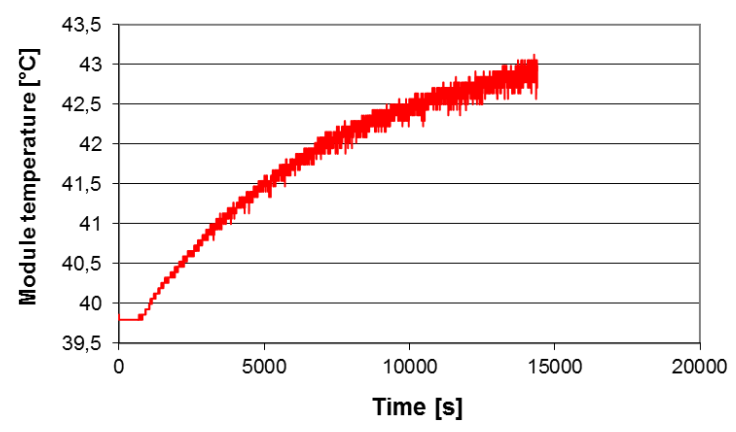

Figure 15: Increase of the SC module temperature during life testing at $40{ }^{\circ} \mathrm{C}$

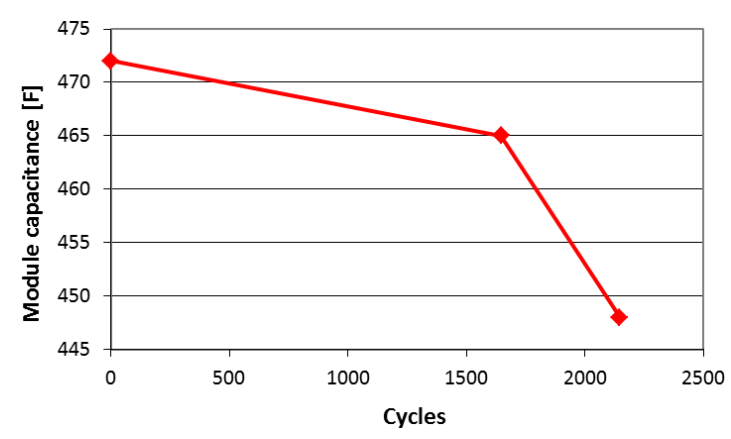

Figure 16: SC module capacitance degradation during ALTRA micro-cycle high temperature testing
The final module capacitance decreased of about $4 \%$ at the end of the high temperature cycling, as shown in Figure 16.

Finally, thermal analysis with infrared camera was also performed on the SC module at RT with limited increase of temperature, which reached a maximum of $29.1{ }^{\circ} \mathrm{C}$. The reached temperature value even during testing at $40{ }^{\circ} \mathrm{C}$ has always been well below the maximum recommended value, giving clear indications about the limited need of thermal management in real operations.

\section{Safety/abuse testing: vibration}

ENEA work has been concentrated on the definition and execution of mechanical abuse testing on one Li-ion and two SC modules, with focus on vibration tests. These tests have been carried out with an electro-dynamic shaker in the ENEA Vibration Hall, resulted compatible, after experimental verification, with the selected test procedure.

The complete test was performed as follows:

1. the SOC of the module was put at $80 \%$ (HEV application);

2. set the power spectrum density (PSD) vs. frequency as shown in Table 8;

3. test duration of 8 hours for each of the three planes of the module under test.

Table 8: Values of PSD at various frequencies for vibration test.

\begin{tabular}{|c|c|}
\hline Frequency, $\mathrm{Hz}$ & $\mathrm{PSD},\left(\mathrm{m} / \mathrm{s}^{2}\right)^{2} / \mathrm{Hz}$ \\
\hline 10 & 20 \\
\hline 55 & 6.5 \\
\hline 180 & 0.25 \\
\hline 300 & 0.25 \\
\hline 360 & 0.14 \\
\hline 1000 & 0.14 \\
\hline 2000 & 0.14 \\
\hline
\end{tabular}

For Li-ion module, no significant reduction of capacity was registered after the vibration tests. Additionally, to further control module integrity and correct operations, an infrared camera was used for thermographic analysis.

The module showed a response up to hazard level 0 [3], with no venting, fire, electrolyte leakage, rupture or explosion. The visual control after each vibration tests allowed for the verification of absence of any evident failure or break in the case. Electrical tests, supported by thermal analysis, confirmed that also internally there was no damage able to modify or reduce the electrical 
performances and the thermal behaviour of the module.

For SC modules, two configurations have been tested: one with an ABS (Acrylonitrilebutadiene-styrene) case and the other one, only for comparison, with a polypropylene (PP) case. The ABS module showed a response up to hazard level 1 [3]. This means that there was no venting, fire, or explosion, but there were physical damages to the module case with undefined small leakages. The visual control after each vibration tests allowed for the verification of the small physical damages of the case. However, electrical tests, supported by thermal analysis, confirmed that internally there was no damage able to modify or reduce the electrical performances and the thermal behaviour of the module.

\section{Conclusions}

The experimental characterization of Li-ion and SC cells and modules has been functional to the complete determination of the technical performances and their suitability to the specific applications to the $\mathrm{HEV}$ developed in the $\mathrm{HCV}$ project. The experimental results substantially have confirmed the general good behaviour of the selected cells and the assembled modules:

1. The characterizations have verified the nominal characteristics of the samples with a negligible spread of values: a confirmation of mature production level.

2. The power capability of Li-ion module is relevant and adequate for the applications.

3. The thermal behaviour of $\mathrm{Li}$ modules is considered good because no significant increase in temperature has been measured, even without thermal management (or cooling) system.

4. The cycle life with standard cycles, accelerated cycles and HCV-cycles has been excellent with negligible deterioration of performances for both storage technologies.

5. The thermal behaviour of $\mathrm{SC}$ module required some control during charging to limit temperature increase: this result is somehow in contrast with the initial indication of no necessity of cooling system.

6. All the attempts (with different cycles and higher temperatures) to accelerate performance decline of $\mathrm{Li}$ and SC module performances have not been effective in giving clear indications on how to model their behaviour and allow for an estimation of SOH (State Of Health).

In conclusions, the complete analysis of the life testing activities at ENEA showed that the Li-ion cells and modules used in the $\mathrm{HCV}$ project are quite insensitive to different types of profiles in terms of performance decline, with the only exception of storage at high temperature for the cells.

For the SC cells and modules, the tests on cells showed a limited degradation of the capacitance as a combined effect of the life cycling and of the use of higher working temperature, while minor mechanical damages of the module case during vibration tests had no impact on the electrical performances of the tested module.

\section{Nomenclature}

ABS Acrylonitrile-butadiene-styrene

AIT Austrian Institute of Technology

BOL Beginning of Life

BSF Battery scaling factor

EC European Commission

EIS Electrochem. Impedance Spectroscopy

EOL End Of Life

ESR Equivalent Series Resistance

ESS Energy Storage System

HCV Hybrid Commercial Vehicle Project

HD Heavy duty

HEV Hybrid Electric Vehicle

LFP Lithium Iron Phosphate

PP polypropylene

RT Room Temperature

SC Supercapacitors (or electrochemical capacitors)

$\mathrm{SE} \quad$ Specific Energy, Wh/kg

SOC State-Of-Charge, $\%$

$\mathrm{SOH}$ State Of Health

SP SubProject

\section{Acknowledgments}

The research leading to these results has received funding from the European Union Seventh Framework Programme (FP7/2007-2013) under grant agreement no. 234019 for the Hybrid Commercial Vehicle (HCV) Project.

\section{References}

[1] M. Conte, Energy storage tailored-test programme for HD hybrid vehicles in a European Project, EVS-27, Barcelona, November 2013. 
[2] M. Conte, et al., Energy Storage System Studies for Heavy Duty Hybrid Electric Vehicles in the EC HCV Project, Transport Research Arena (TRA) 2014, Paris, April 2014.

[3] AIT, Hybrid Commercial Vehicle (HCV) FP7Project, Abuse Test Plan for Li Batteries and SC, Technical Report D3100.4, 2010. http://www.hcv-project.eu/publications.shtml

[4] ENEA, Hybrid Commercial Vehicle (HCV) FP7-Project, Electrical test plan for Li batteries, Technical Report D3100.2, 2013.

[5] ENEA, Hybrid Commercial Vehicle (HCV) FP7-Project, Electrical test plan for SC, Technical Report D3100.3, 2013.

[6] M. Ceraolo, State-Of-Charge evaluation of supercapacitors for usage in hybrid vehicles, European Electric Vehicle Congress, Brussels, Belgium, December, 2014.

[7] T. Huria, et al., State of charge estimation of high power lithium iron phosphate cells, Journal of Power Sources, Journal of Power Sources, doi:10.1016/j.jpowsour.2013.10.079, 249 (2014), 92-102.

[8] T. Huria, et al., High Fidelity Electrical Model with Thermal Dependence for Characterization and Simulation of High Power Lithium Battery Cells, IEEE Electric Vehicle Conference, March 2012.

\section{Authors}

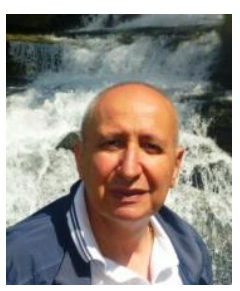

Mario Conte is responsible of the ENEA's Energy Storage Systems Coordination Unit. He is involved in research projects on batteries, supercapacitors, hydrogen storage for mobile and stationary applications. He is technical secretary of the Italian EV association, board member of AVERE and WEVA and vice-chairman of the IEA IA on EVs and HEVs.

Fabrizio Alessandrini is an industrial

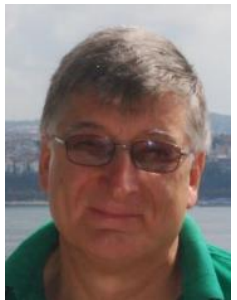
chemist. Since 1982 he is researcher at ENEA and has been working on basic and applied research related to the study of materials and systems for electrochemical storage and conversion. Main topics studied are: lithium batteries, sodium-sulphur batteries, polymer electrolytes, conductive ceramics and ionic liquids.
Manlio Pasquali got his degree in

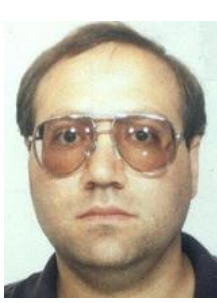
Electrical engineering at the University 'La Sapienza' of Roma in 1997. Actually he is researcher at ENEA and works on computer simulations in power systems, storage batteries, electric and hybrid vehicles, with definition and application of simplified test profiles.

Ennio Rossi is a mechanical engineer and, since 1994, has been involved in electric and hybrid vehicles, developing and applying test methodologies and carrying out testing on scooters, cars and light commercial vehicles. $\mathrm{He}$ is also working on supercapacitor and battery testing and in a program for the realization of hybrid vehicles.

Vincenzo Sglavo is a mechanical engineer and researcher at ENEA, where he is working in the "Low Environmental Impact Vehicles" Laboratory, especially in the section relating to electrochemical batteries and supercapacitors. His research work is related to storage devices testing, with focus on Lithium-ion and lead-acid batteries, supercapacitors.

Francesco Vellucci is a mechanical engineer and has been working in the

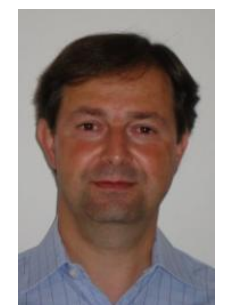
ENEA's "Low Environmental Impact Vehicles" Laboratory, especially on electrochemical batteries and supercapacitors. He is involved in preparation of standards in the Italian IEC for electric vehicles and in charge of testing activities on energy storage systems. 